\title{
Techniques for Prioritizing the Elements of Web-GIS Usability
}

\author{
Ezekiel Kuria Mwangi \\ KCA University \\ P. o. Box 56808-00200 \\ Nairobi
}

\author{
Stephen Kimani \\ Jomo Kenyatta University of \\ Agriculture \& Technology \\ P. o. Box 62000-Nairobi
}

\author{
Agnes Mindila \\ Jomo Kenyatta University of \\ Agriculture \& Technology \\ P.o.Box 62000-Nairobi
}

\begin{abstract}
Different elements of Web-GIS usability have different impact during design and usability evaluation of the Web-GIS websites. It is important therefore to prioritize Web-GIS usability elements based on their impact on usability. The techniques used for prioritizing usability elements of WebGIS are important to developers of Web-GIS systems during design and usability evaluation. Existing techniques used to prioritize elements of usability were compared, with a view of proposing appropriate method for prioritizing Web-GIS usability elements. The research compared the compurank method-which is based on an algorithm, scenario-based ranking method (SBRM) and the Multicriteria user satisfaction analysis (MUSA). The MUSA method was found to be the most appropriate method that developers can use to prioritize Web-GIS usability elements because it involves collecting user needs directly from the users.
\end{abstract}

\section{Keywords}

Web-GIS Prioritization Techniques, Ranking, Usability Elements, and Functionality

\section{INTRODUCTION}

According to [1], Web-GIS is an online application with a web-based map interface that enables users to interact with spatial information and create customized maps. [2] stated that Web-GIS applications usability need to be continuously evaluated to improve on their usability.

The use of GIS applications dates back 60 years ago, [3] observed that the emergence and wide use of World Wide Web (www) made Web-GIS applications more common. For a website to attract and retain visitors, it should emphasize on usability elements [4].

The use of GIS has grown over the years, the number of users is immensely increasing and large datasets are being handled in projects and shared across users and communities. Rapid growth in ICT is increasing the demand and urge for better online data sharing platforms thus creating the need for the development of web portals by governments, institutions, and the private sector. Data sharing platforms have been developed which ease the sharing of spatial data between end users and organizations. This has led to sprouting of Web-GIS systems for use in various GIS related fields. Web-GIS has been stated to be a cheap and simple way of disseminating geographical information systems data and processing tools, it makes it easy to distribute maps and processing tools without time and location restriction to users.

According to [6] Web-based GIS applications have gained popularity because of global reach-this is because they broadly support HTTP. A huge user base: while traditional standalone GIS could only be used by one person at a time, many users use Web-GIS simultaneously.

Low cost: most content on the web is basically free of charge to end users, it's the same case with web GIS. Web-GIS users don't need any license or to buy any software to use web GIS. It also enables sharing so that workers of the same company working in disparate areas can easily share one Web-GIS, set up at the headquarters for instance. Easy to use: the nature of Web-GIS is that they are meant to be used by non-experts thus they must be designed so that they are easy to use. This is because unlike Desktop GIS whose users undergo months of training and are generally experienced in the use of GIS, Web-GIS users are deemed to be novices with no prior knowledge of GIS. They should be designed to be simple, intuitive, and much easier to use as compared to Desktop GIS.

\subsection{Problem statement}

During the interface design process usability evaluation plays an important role that includes interactive cycles, designing prototyping and evaluating again until the designers are satisfied that the interface is adequately usable. Thus, the ideal situation is to conduct extensive evaluations for all the parts of the web map. However due to budget constraints and time limitations it's not always possible to conduct exhaustive usability evaluations all the time. Usability elements play a vital role in confirming the usability of software during the development process and especially during usability evaluation. Different usability elements influence a typical characteristic associated with different software. The influence of each usability element will vary during the usability evaluation process and development in general. It's therefore useful to determine which elements affect which software characteristic and even more significantly rank the usability elements in order of importance during evaluation and development. This implies creating a priority list of elements of usability to allow developers to allocate the limited software development resources in the most optimum way. This is in recognition of the fact that development resources such as time and manpower are usually limited and must be allocated in the most optimum way possible. No method has so far been proposed in literature for ranking the usability elements of Web-GIS.

This paper therefore aims at proposing a method that can be used to rank/prioritize the usability elements of Web-GIS after comparing the existing methods.

\subsection{OJECTIVES}

The study aimed to establish the most appropriate method that can be used to prioritize the usability elements of web GIS. The focus was on the following specific objectives;

a) To establish methods that can be used to prioritize the usability elements of Web-GIS usability. 
b) To compare the various methods that can be used to prioritize the usability of Web-GIS established above

c) To propose appropriate method for prioritizing Web-GIS usability elements

\section{REVIEW OF THE LITERATURE}

Web-GIS proliferation has evoked a paradigm-shift in geographic content analysis from the traditional desktop software toward GIS-centric web applications [7]. The primary goal of Web-GIS is to enable users to easily find, visualize and analyze embedded spatial information in the data source as [8] and [1] documented. Web-GIS today is being applied in diverse fields due to its ability to display and allow quick manipulation of geographical data. In addition, it's estimated that up to $85 \%$ of all data have a spatial component and, thus can easily be represented using Geographic Information Systems [9].

According to [10] many organizations and individuals can significantly benefit by harnessing the powerful graphical displays and analytical potentials of Web-GIS. However, it is acknowledged among researchers and experts that Geographic Information Systems programs and software are inherently difficult to use

Many usability studies have been performed with professional geospatial experts as participants. The attempt was to make these programs more accessible to the geospatial specialists. Participants often gave-up in the middle of the participation process because of great learning barriers and complicated interfaces [11]. Further, there is a clear ethical need to protect and support non- expert users trust assessments before they decide to rely on online maps, this can be achieved by improving their spatial skills.

Moreover [3] and [1] are in agreement that traditional GIS has been a reserve for experts who are well trained in the use of its complex software. Issues of usability were thus not so pronounced like today. This is because most GIS systems require skilled knowledge of the system to operate them, and are more focused on technology and functionality rather than usability [9]. Users with no GIS training will make the most from any of the off-the-shelf GIS software [8]. This is made worse by the very nature of GIS which demands not just general computer literacy but also some spatial understanding from the user. Effective spatial thinking, demands a high degree of user interactivity, where Web-GIS are supposed to be easy to use and comprehend. Web-GIS applications designed for non-experts should be tailored to support and guide users as they try out ordinary assignments such as searching and filtering information. Prominent researchers realized that users will need to be able to query the spatial data and to print clear outputs for their own usage [12].

According to [10] usability evaluation of Web-GIS is an important aspect of interaction design that helps to find out the exact user needs and requirements. [11] defined usability evaluation as the process of systematic collection of data on how people use the system. [13] stated that map design should be user-oriented and be based on knowledge of elements of usability-they include recognition, navigation, speed, search, layout, style of writing, hyperlinks, interaction, accessibility and pictures and multimedia.

\subsection{Elements of Web-GIS Usability}

The International Cartographic Association established issues of map usability within its research agenda. According to this agenda, map design should be user oriented and be based on knowledge of the elements of usability. The criteria for WebGIS usability evaluation should comprise both the usability elements of the map and usability elements of the website.

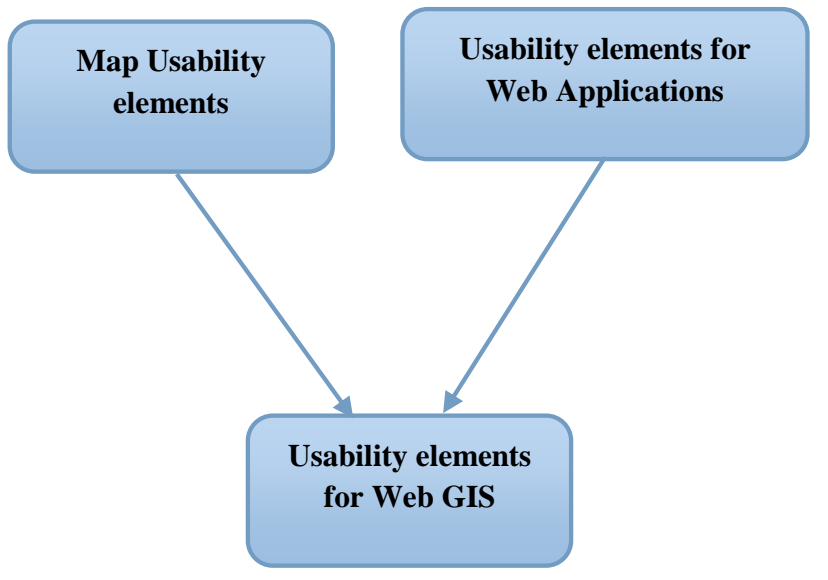

Figure 1: Web-GIS Usability Elements

[14] set out to uncover the main elements of GIS usability and listed them as satisfaction, interaction, and content. [6] proposed a similar set of elements for testing the usability of Web-GIS based on the elements, effectiveness/user performance, usefulness, and user Reaction.

According to [15] website usability elements are; accessibility, interactivity, personalisation, privacy and security, content, learnability, design structure, navigation, performance and memorability.

\subsection{Prioritization of website usability elements}

Different website usability elements will have different or varying impactsไrole during the usability evaluation process. It is important to determine the relative importance of each element during the usability evaluation process. Due to limited software development resources, it is important to perform a priority assessment of the elements of website and focus the available resources on higher priority elements [16].

\subsection{Prioritization of Web-GIS Usability elements}

Although Web-GIS are complex and therefore should be designed in ways that allow ordinary users to easily interact and fulfill their requirements without problems, there is no work so far that focuses on the concern of prioritizing elements of Web-GIS usability to balance their trade-offs in achieving the usability of such systems [16]. During the interface design process usability evaluation plays an important role that includes interactive cycles, designing prototyping and evaluating again until the designers are satisfied that the interface is adequately usable [22]. Thus, the ideal situation is to conduct extensive evaluations for all the parts of the web map. However due to budget constraints and time limitations it's not always possible to conduct exhaustive usability evaluations all the time.

According to [15] effort has been made to rank website usability elements in order of their importance. The research found out that on each e-commerce website, certain usability attributes are likely to be more crucial to success. The research indicated that Content is the most important of the 6 major categories $(60 \%)$. It suggests that information is the primary reason when the customer visits an e-tourism website. 
Personalization ranks second in importance in the e-tourism website's usability (57.5\%). Customers care about being recognized by the website and being treated as an individual. The third important category is Interactivity $(53.75 \%)$. This suggests that customers need to be able to communicate and collaborate with other customers. Navigation and Interactivity have approximately the same importance $(52.5 \%)$ of the customers selected navigation as an important factor that affects their decision to buy or not to buy from an e-tourism website. The fifth important category is Design-Structure $(43.75 \%)$. It is important for the users when they visit the website for the first time to find a professional homepage describing the purpose of this website and containing suitable elements. Accessibility has the least importance among the six major categories of usability evaluation, about 39\%. The general interface design principles and Web design principles are also valid for the design of Web mapping applications.

\subsection{Existing techniques for prioritizing software usability attributes}

Understanding the usability goal of software and confirming whether the elements related to usability are in line with the study goal and can result to a very usable product. However, these elements need to ranked/prioritize in order of importance with regard to software usability. Prioritizing is one of the techniques used to resolve trade-off between different usability elements. It works by prioritizing and ranking the elements according to the context given by stakeholders. The achieved priority assists the developers to focus on the higher-priority elements and ensures that the product is high in usability. There are several methods for ranking usability elements which include: algorithmic approach, scenario based ranking method and multi-criteria method as described;

\subsubsection{The algorithmic approach}

[17] Stated that algorithmic approach is used to rank the usability attributes in an empirical manner. It a well-structured method for the prioritizing usability attributes when it comes to designing and developing software that can be most usable. Three key parameters are used to define software development project. The parameters are project development approach, project type and project size. This approach is also known as compurank, ranks of usability attributes and are calculated based on the mean dependency values such that the usability attribute with the lowest dependency is given the highest rank. The dependency values for each usability attribute are assigned based on the corresponding weights and the dependency level. Using this method, it's possible to prioritize usability elements generally or in a structured way. The structured way focuses only on the three project parameters; project size $S$, project type $T$, project development approach used $\mathrm{D}$ and $\mathrm{n}$ usability attributes At, $\mathrm{t}=$ $1 \ldots . \mathrm{n}$ these are the elements to be ranked in the order starting from 1 being the highest ranking or most important to $n$. $n$ being the least important. Dependency levels, 11, 12, 13 are also normally associated with the parameters project size, project type and project development approach above respectively. The first step involves allocating weights to influence levels, the weights of influence levels are then assigned to the project parameters for each usability element. Then dependency values (measure of dependency of a usability element An where $n=1 ., ., ., . U$ on project parameters on any given project) of each usability element At, in a given project, project dependency value (the overall dependency of an element pertaining to a software project) of each usability element At in different software projects and Mean
Dependency Values of each usability element At in all existing software projects are then estimated. At the end of the day ranks are assigned to the usability elements depending on their respective mean dependency values so that the element with the least mean dependency value will be assigned the highest rank and the one with the meanest dependency value assigned the lowest rank.

\subsubsection{Scenario Based Ranking Method (SBRM)}

Scenario Based Ranking Method (SBRM) is used to rank usability attributes in a software project. The method begins with identification of the software project and then identification of the scenarios. Scenarios are identified by defining the scenarios of each usability attribute and determining core characteristics of the usability attributes. The scenarios are evaluated for every usability attribute in each project and then the level of acceptance and usability influence are computed. Finally, ranks of the usability attributes are assessed through calculating the overall influence [21]. The aim is to list a combination of events describing how a situation might occur in real situation. A scenario can be used to test certain aspects of the software being designed. For example, the designer may be interested in determining whether certain features are easy to use or require user training. Thus, the scenario will be designed to test ease of use [17]. Scenarios provide a subjective as well as an objective way to investigate usability elements and us to understand the rationale behind the importance of usability elements. Scenario based ranking of usability elements is a useful way for incorporating usability elements with preferences as usable software is designed and developed. The method has the advantage of being more flexible and includes user-oriented assessment of software usability attributes.

\subsubsection{Multi-criteria Satisfaction Analysis}

[16] Describes prioritizing usability elements as a multicriteria decision-making problem which involves evaluating multiple conflicting criteria and coming up with a trade -off resolution at the final analysis (Read on requirements prioritization methods). MUSA (Multi-criteria Satisfaction Analysis) is a set of customer preferences in a quantitative mathematical function values. Data is collected using a questionnaire that allows each customer to evaluate the offered services. The questionnaire requires each participating customer to express both their global and individual satisfaction for each of the criteria characteristics of the product or service. The MUSA method is the applied to assess the global function $\mathrm{Y}^{*}$ and the partial function $\mathrm{X}^{*}$ using the customer's responses $\mathrm{Y}$ and $\mathrm{xi}$ respectively. The MUSA method comes with some advantages such as: the result allows for continuous improvement of the system, using action diagrams the method indicate the weak areas where the business must be improved to enhance customer's satisfaction. More importantly it provides priorities that should be given to each of the actions aimed at improving the system. The main requirements for this method are monoticity, meaning that when any two alternatives are compared, an improvement of one of them on at least one criterion from should not deteriorate its comparison to the other alternative, exhaustivity which means that, any two alternatives having the same evaluations on all criteria should be considered indifferent, and non-redundancy, which means that, the deletion of any criterion will contradict one of the two conditions [20]. 


\section{METHODOLOGY}

To uncover the most appropriate method for prioritizing elements of Web-GIS usability, the creative process was derived from [18]. Problem analysis task was the first, it involved reviewing existing literature looking for information that could enhance understanding of the methods that can be used to prioritize elements of the usability of Web-GIS. Relevancy of the topic formed an important criteria used for analyzing all the articles and peer reviewed papers. All the papers used in the survey are peer reviewed.

\section{FINDINGS AND DISUSSION}

Web-GIS developers are faced with scarcity of resources including and not limited to development time and resources. There is need to prioritize usability elements so that the product is optimized for use. There are several methods used for ranking or prioritization of various aspects of life. However the ones that have been used to rank elementslattributes of software usability include: The compurank/ algorithmic method, the scenario based ranking method and the Multicriteria user satisfaction analysis method as stated in section 2 above, in the compurank method, a software development project is defined by three key parameters; project development approach, project type and project size. Ranks of usability attributes are calculated based on the mean dependency values such that the usability attribute with the lowest dependency is given the highest rank. Its main advantage is that, it provides a well-structured method for the prioritization of software usability elementslattributes. It affords the developers a systematic and scientific method for the prioritization of software usability elements during the process of software development and evaluation. The scenario based ranking method employs the use of scenarios to rank software usability elementslattributes. Its strengths include the fact that its more user oriented as compared to the compurank method. The Multicriteria user satisfaction analysis method has been applied to prioritize the elements/attributes of software usability. It involves the use of questionnaires to sample users who give their views after using a given software. Its main advantage is the fact that it gets the direct views of the user thus will give results that are close to the user's needs.

The study found MUSA to be the most appropriate method to prioritize the elements of Web-GIS usability since Web-GIS is meant for novice users such as the public. It was noted that the Web-GIS as it is today, is being used by users with varying levels of experience. Thus, some of these users find the new interactive techniques difficult to use and may not utilize them to the optimum the design of most Web-GIS does not consider all the needs of novice users, and that many GIS systems are cumbersome and difficult to use, and as depicted by [19], they usually have a large tool bar that the user must learn before they can proficiently use the system.

Evaluating the elements of the usability of Web-GIS is important so that designers will pay more attention to such elements during design. It is important that most usability issues are solved during usability evaluation. This helps to improve the evaluation process and the overall usability of websites.

Based on the available literature, it is clear that Web-GIS contains both the elements of the website and elements of the map, which is usually embedded on the website. To affect the usability of a Web-GIS then we need to consider both usability elements of the map and usability elements of the websites. The net effect of these two produces the overall overriding influence on the usability of any Web-GIS.

\section{CONCLUSION}

Web-GIS is popular nowadays. It's used by people who are not trained in GIS. It's necessary to make this website usable for novice users. The elementslattributes of Web-GIS usability are derived from elements of map usability and websites usability. It is important to rank the since different elementslattributes will have different impacts on the usability of Web-GIS. Methods that can be used to prioritize or rank elementslattributes of software usability include the compurank method, the scenario based ranking method and the multicriteria user satisfaction analysis method. Comparing these three prioritization methods it's clear that the most appropriate method for rankinglprioritizing elements of WebGIS usability is the multicriteria user satisfaction analysis method.

\section{RECOMMENDATIONS}

The research has looked at the possible methods for prioritizing the elements of Web-GIS usability. From available literature the methods include compurank, scenario based ranking method and multicriteria user satisfaction analysis method. The three methods have been applied to websites, but none has been applied on Web-GIS. Further work therefore should be geared towards applying the methods in Web-GIS development to determine the rankinglpriorities of the elementslattributes of Web-GIS usability.

\section{FURHTER WORK}

Based on the findings and the results of the study, the researcher recommends:

Further research to confirm the applicability and successful use of Multicriteria user satisfaction analysis method to prioritize the usability elements of Web-GIS. Although the method has been successfully used to rank the usability elements of commercial websites it's important to experiment using the method on ranking of Web-GIS usability elements.

\section{REFERENCES}

[1] N. Kong, T. Zhang and I. Stonebraker, "Common Metrics for Web-based Mapping Applications in Academic Libraries," Libraries Faculty and Staff Scholarship and Research, vol. CV, pp. 1-18, 2014.

[2] D. W. W. Y. K. Chaowei (Phil) Yang, "Performanceimproving techniques in web-based GIS," International Journal of Geographical Information Science, vol. XIX, no. 3, p. 319-342, 2005.

[3] M. Düren and T. Bartoschek, "Assessing the Usability of WebGIS for Schools," Berlin, 2013.

[4] E. B. Visser and M. Weideman, "An Empirical Study on Website Usability Elements and How they Affect Search Engine Optimisation," SA Journal of Information Management, vol. XIII, no. 1, pp. 2-9, 2011.

[5] N. Andrienko, G. Andrienko, H. Voss, F. Bernardo, J. Hipolito and U. Kretchmer, "Testing the Usability of Interactive Maps in CommonGIS," Cartography and Geographic Information Science, vol. XXIX, no. 4, pp. 325-342, 2002.

[6] Z. A. Khan and M. Adnan, Usability Evaluation of Webbased GIS Applications, Ronneby-Sweden: Blekinge Institute of Technology, 2010. 
[7] F. X. D. Mpagi, "A User Satisfaction Evaluation of Web GIS Platforms in Public Service Delivery: A Case Study of Winona County," Saint Mary's University of Minnesota University Central Services Press. Winona MN, vol. XV, pp. 1-8, 2013.

[8] M. .. Haklay and A. Zafiri, "Usability Engineering for GIS: Learning from a Screenshot," The Cartographic Journal, vol. XLV, no. 2, pp. 87-96, 2008.

[9] A. Gonzalez, A. Gilmer, R. Foley, J. Sweeney and J. Fry, "Developing and Applying a User-friendly Web-based GIS for Participative Environmental Assessment," ResearchGate, vol. XXXVIII, no. 7, p. 918 - 935, 2007.

[10] S. Boroushaki and J. Malczewski, "ParticipatoryGIS: A Web-based Collaborative GIS and Multicriteria Decision Analysis," URISA Journal, vol. XXII, no. 1, pp. 23-32, 2010 .

[11] Y. Meng and J. Malczewski, "Usability Evaluation for a Web-Based Public Participatory GIS: A Case Study in Canmore, Alberta," European Journal of Geography, pp. $1-40,2009$.

[12] O. Gudes, T. Yigitcanlar, Y. Tal and Y. Bar-Lavi, "Innovative Cartography Standards for Web-GIS Portals: Case Study of the 'Survey of Israel's' Web-GIS Portal," Proceeding of the International Federation of Surveyors (FIG) Working Week 2009 Surveyors Key Role in Accelerated Development, 3-8 May 2009, pp. 2-15, 2009.

[13] M. Konecný, P. Kubícek, Z. Stachon and C. Šašinka, "The Usability of Selected Base Maps for Crises Management-Users' Perspectives," SpringerLink, vol. III, no. 4, p. 189-198, 2011.
[14] M. Wachowicz, W. Vullings, J. Bulens, H. d. Groot and M. v. d. Broek, "Uncovering the Main Elements of GeoWeb Usability," Lisbon-Portugal, 2005.

[15] K. L. M. Rami Muhtaseb, "Applying a Multicriteria Satisfaction Analysis Approach Based on User Preferences to Rank Usability Attributes in E-tourism Websites," Journal of Theoretical and Applied Electronic Commerce Research, vol. VII, no. 3, pp. 28-48, 2012.

[16] S. P. L. C. L. Chun Yong Chong, "Prioritizing and Fullfilling Quality Attributes for Development Through Application of Fuzzy Analytic Hierarchy Process and Software Development Guidelines," Malaysian Journal of Computer Science, vol. XXVII, no. 1, pp. 1-19, 2014.

[17] K. Paithankar and M. Ingle, "Influence of Parameters on Usability Attributes in Software Projects," PutrajayaMalaysia, 2011.

[18] S. N. Mwendia, P. Waiganjo and R. Oboko, "Dynamic Heuristics: Greedy Search: A Mobile Information Retrieval Algorithm for Ambient Learning Systems," AfriCHI, no. 16, pp. 69-79, 2016.

[19] S. Li, S. Dragicevic and B. Veenendaal, Advances in Web-Based GIS, Mapping Services and Applications, London: Tailor and Francis Group, 2011.

[20] V. M. R. S. Salvatore Greco, "Robust Multiple Criteria Ranking Using a Set of Additive Value Functions," 2007.

[21] A. Mavin, "Determining Socio-Technical Systems Requirements: Experiences with Generating and Walking Through Scenerios," in Elevent IEEE International Conference on Requirements Enginering.

[22] A. Marcus, Design User Experience and Usability-Web, Mobile and Product Design, Las Vegas, 2013. 